\title{
Ring-Opening Metathesis Polymerization of Coumarin-Containing Norbornene
}

\author{
Mikhail A. Tlenkopatchev, Serguei Fomine, ${ }^{\dagger}$ Lioudmila Fomina, \\ Ruben GaviÑo, and Takeshi OGawa \\ Instituto de Investigaciones en Materiales, Universidad Nacional Autónoma de Mexico, \\ Circuito Exterior, Ciudad Universitaria, \\ Apartado. Postal 70-360, Coyoacán, México DF 04510, México
}

(Received October 7, 1996)

KEY WORDS Coumarin / Norbornene / Metathesis Polymerization / Luminescence /

Coumarin-containing polymers have attracted much attention due to their fluorescent properties and physiological activities. Thin films fabricated from such polymers are promising for application, to optoelectronic devices. Polymeric electroluminescence materials have advantages over inorganic compounds, such as easy processability for preparation of thin films with high optical quality by simple casting and color tunability throughout visible spectrum.

The literature shows very few reports on coumarin containing polymers. Coumarin-containing polymers with physiological activities ${ }^{1-5}$ and photoconducting properties were reported by authors. ${ }^{6}$ Novel polyamides with 3,6-disubstituted coumarin units in the main chain have recently been synthesized and characterized. ${ }^{7}$ The polymers show strong photoemission in blue-green region and electroluminescence with turn on voltage of $3-5 \mathrm{~V}$.

In the past several years norbornene monomers have been the subject of intense interest because of their facile functionalization, high reactivity in the ring-opening metathesis polymerization (ROMP) and the ring-preserving polymerization (RPP). Novel light emitting electro- and photoluminescent polynorbornenes have been synthesized by ROMP and RPP of norbornenes containing phenylenevinylene oligomer ${ }^{8}$ and fluorescein ${ }^{9}$ units in the side chain. One easy way to produce coumarine-containing polymers is to synthesize a coumarine-containing monomer followed by its ROMP. Polynorbornenes are amorphous optically transparent materials of importance for optical applications. Moreover, high molecular weight polymers with good mechanical properties can be obtained by ROMP using appropriative catalysts tolerating functional groups.

The present report describes the synthesis of a new light emitting polynorbornene by ring-opening metathesis polymerization of a coumarin-containing norbornene (NBC) using $\mathrm{Ru}$ and Os based catalysts. Recent works ${ }^{9-12}$ suggest that $\mathrm{RuCI}_{3}$ and $\mathrm{OsCI}_{3}$ hydrates and their complexes are much more tolerant to heteroatoms in the monomer than conventional catalysts containing tungsten halides or molibdenum and metalloorganic cocatalysts.

\footnotetext{
† To whom correspondence should be addressed.
}

\section{EXPERIMENTAL}

\section{Materials}

Polymerization solvents, chlorobenzene, and toluene, were distilled over calcium hydride before use. $\mathrm{N}$ Methylpyrrolidone (NMR) and pyridine were distilled over $\mathrm{CaH}_{2} . \mathrm{RuCI}_{3} \times \mathrm{H}_{2} \mathrm{O}$ and $\mathrm{OsCI}_{3} \times \mathrm{H}_{2} \mathrm{O}$ (Aldrich) were used as received. $\mathrm{RuCI}_{2}\left(\mathrm{PPh}_{3}\right)_{3}$ was prepared according to the literature. ${ }^{13}$ Other reagents (Aldrich) were used as received (2-Norbornenyl)methyltosylate (2) was prepared as described previously. ${ }^{9}$

\section{Monomer Synthesis \\ 7-[(2-Norbornenyl)methoxy]coumarin $(N B C)$}

A mixture of 7-hydroxycoumarin (3) $(2.9 \mathrm{~g}, 17.9$ mmol), (2-norbornenyl)methyltosylate (3) (5 g, 18.1 $\mathrm{mmol}), \mathrm{K}_{2} \mathrm{CO}_{3}(2.9 \mathrm{~g}, 21 \mathrm{mmol})$ and NMR $(25 \mathrm{ml})$ was stirred overnight at $60^{\circ} \mathrm{C}$. The reaction was poured into diluted hydrochloric acid, precipitate formed was filtered off, dried and crystallized from a mixture of hexanebenzene. Yield $64 \%, T_{\mathrm{m}}=110-111^{\circ} \mathrm{C}, \mathrm{IR}\left(\mathrm{cm}^{-1}\right) 3055$ (C-H, arom, vinyl) 2966, 2868 (C-H aliph), 1720 (C=O ester), $1616\left(\mathrm{C}=\mathrm{C}\right.$ arom). ${ }^{1} \mathrm{H}$ NMR (ppm) in $\mathrm{CDCI}_{3}$ $7.60\left(\mathrm{~d}, 1 \mathrm{H}, J=9.6 \mathrm{~Hz}, \mathrm{H}^{4}\right), 7.32\left(\mathrm{~d}, 1 \mathrm{H}, J=8.4 \mathrm{~Hz}, \mathrm{H}^{5}\right)$, $6.79\left(\mathrm{~d}, \mathrm{~d}, 1 \mathrm{H} J_{\text {ortho }}=8.4 \mathrm{~Hz}, \mathrm{H}^{6}\right), 6.72(\mathrm{~d}, 1 \mathrm{H}, J=2.4 \mathrm{~Hz}$, $\left.\mathrm{H}^{8}\right), 6.16\left(\mathrm{~d}, 1 \mathrm{H}, J=9.6 \mathrm{~Hz}, \mathrm{H}^{3}\right), 6.18-5.92(\mathrm{~m}, 2 \mathrm{H}$, olefin), $3.74-3.58\left(2 \mathrm{H}, \mathrm{OCH}_{3}\right), 3.00-0.62(\mathrm{~m}, 7 \mathrm{H}$, aliph). ${ }^{13} \mathrm{C} \mathrm{NMR}(\mathrm{ppm})$ in $\mathrm{CDCI}_{3}: 162.5\left(\mathrm{C}^{2}\right), 160.8$ $\left(\mathrm{C}^{7}\right), 156.0\left(\mathrm{C}^{9}\right), 143.3\left(\mathrm{C}^{4}\right), 137.8,132.1,128.8$-(olefin, $\left.\mathrm{C}^{5}\right), 112.9,112.8,101.6\left(\mathrm{C}^{6}, \mathrm{C}^{3}, \mathrm{C}^{8}\right), 112.5\left(\mathrm{C}^{10}\right), 72.2$ $\left(\mathrm{OCH}_{2}\right), 49.50,44.00,42.35,38.3,29.1$ (aliph) (Scheme 1).

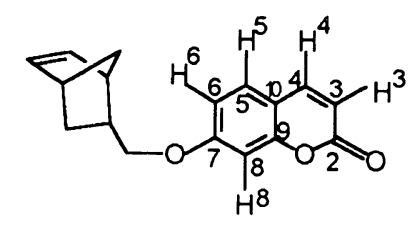

\section{Polymerization}

The metathesis polymerization of $\mathrm{NBC}$ was carried out using $\mathrm{RuCI}_{3} \times \mathrm{H}_{2} \mathrm{O}$ and $\mathrm{OsCI}_{3} \times \mathrm{H}_{2} \mathrm{O}$ under dry nitrogen atmosphere. The active catalysts was prepared by refluxing of commercial $\mathrm{RuCI}_{3}$ and $\mathrm{OsCI}_{3}$ hydrates in ethanol for 3 hours. ${ }^{9}$ A typical polymerization experiment is as follows: $1 \mathrm{~g}(0.0037 \mathrm{~mol})$ of monomer (NBC) was dissolved in $7 \mathrm{ml}$ of chlorobenzene under dry nitro- 

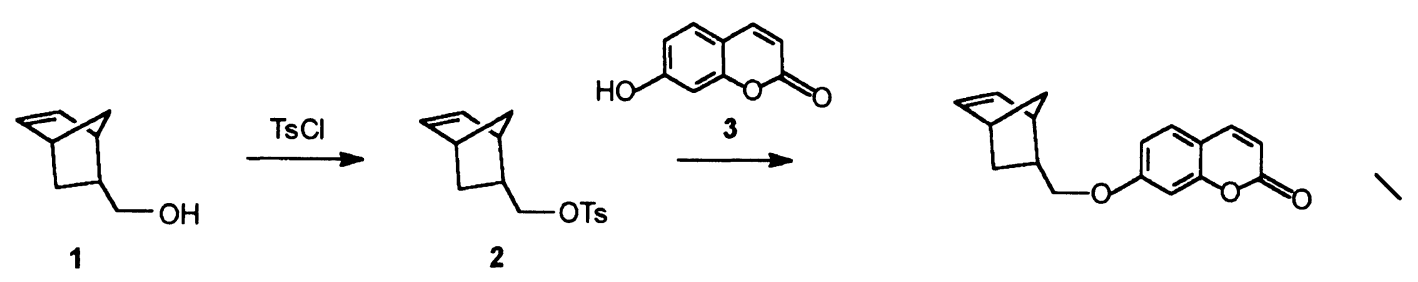

NBC

Scheme 1. Monomer synthesis.
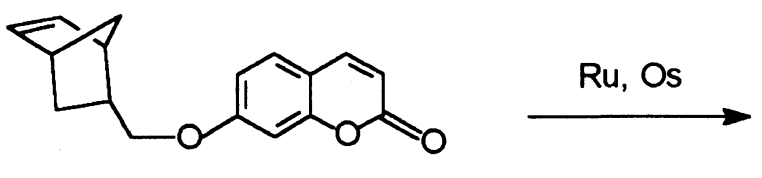

NBC

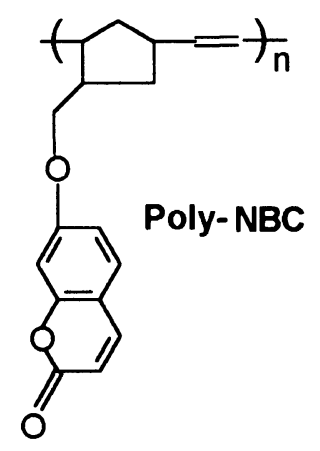

Scheme 2. Polymer synthesis.

gen. To this solution $\mathrm{RuCI}_{3}\left(\mathrm{OsCI}_{3}\right) \times \mathrm{H}_{2} \mathrm{O}$ ethanol solution $\left(0.044 \mathrm{moll}^{-1}\right)(0.4 \mathrm{ml})$ was added. The reaction was carried out at $70^{\circ} \mathrm{C}$ for 8 hours. The polymer formed was precipitated into methanol, filtered off and purified by reprecipitation from chloroform into methanol. The polymer was dried in a vacuum oven at $30^{\circ} \mathrm{C}$ for 24 hours.

\section{Measurements and Sample Preparation}

The molecular weights of polymers were determined using a Varian $9012 \mathrm{GPC}$ instrument at $30^{\circ} \mathrm{C}$ in $\mathrm{CHCI}_{3}$ with polystyrene standard, universal column and a flow of $1 \mathrm{ml} \mathrm{min}{ }^{-1}$ DSC, TMA, and TGA were performed at a heating rate of $10^{\circ} \mathrm{C} \mathrm{min}^{-1}$ under nitrogen with a du Pont 2100 machine. FT-IR-spectra were tanek using a Nicolet 510p spectrometer. UV-visible spectra were taken using a Shimadzu UV-260 spectrometer in thin films spin-coated onto a quartz slide. ${ }^{1} \mathrm{H}$ NMR and ${ }^{13} \mathrm{C}$ NMR were recorded using a Varian spectrometer at $300 \mathrm{MHz}$ and $75.5 \mathrm{MHz}$, respectively, in $\mathrm{CDCI}_{3}$ with trimethylsilane (TMS) as the internal standard. The wide angle X-ray diffractometry was performed on a Siemens D-500 diffractometer. Emission and excitation spectra were measured with a Perkin-Elmer 630-10S fluorimeter using thin films spin-coated onto a quartz slide.

\section{RESULTS AND DISCUSSION}

Monomer NBC was polymerized by $\mathrm{Ru}$ and Os based metathesis catalysts giving high molecular weight coumarin-containing polynorbornene (Scheme 2). The reaction conditions are listed in Table I. As can see from Table $\mathrm{I} \mathrm{OSCI}_{3}$ and $\mathrm{RuCI}_{3}$ hydrates were effective and show comparable activities in ROMP of $\mathrm{NBC} \mathrm{RuCI}_{3} \times$ $\mathrm{H}_{2} \mathrm{O}$ and $\mathrm{RuCI}_{2}\left(\mathrm{PPh}_{3}\right)_{3}$ catalysts produce the polymers with the preferential trans configuration of the double bonds (90-95 mol\% of trans double bonds from ${ }^{1} \mathrm{H}$ $\mathrm{NMR}$ analysis of olefinic protons), whereas $\mathrm{OsCI}_{3} \times$ $\mathrm{H}_{2} \mathrm{O}$ catalyst gives poly-NBC with a mixture of $c i s$ and
Table I. Polymerization of coumarin-containing norbornene (NBC) using Ru and Os based metathesis catalysts ${ }^{a}$

\begin{tabular}{llcccc}
\hline Run & Catalyst & {$[\mathrm{M}] /[\mathrm{Cat}]^{\mathrm{b}}$} & $\begin{array}{c}\text { Polymer } \\
\text { yield } / \%^{\mathrm{c}}\end{array}$ & $M_{\mathrm{n}} / 10^{5}$ & $\boldsymbol{M}_{\boldsymbol{w}} / \boldsymbol{M}_{\mathrm{n}}{ }^{\mathrm{d}}$ \\
\hline 1. $\mathrm{RuCI}_{3} \times \mathrm{H}_{2} \mathrm{O}$ & 100 & 68 & 1.2 & 1.95 \\
2. $\mathrm{RuCI}_{3} \times \mathrm{H}_{2} \mathrm{O}$ & 300 & 45 & 2.4 & 2.02 \\
3. $\mathrm{RuCI}_{2}\left(\mathrm{PPh}_{3}\right)_{3}$ & 50 & 48 & 2.8 & 2.13 \\
4. $\mathrm{OsCI}_{3} \times \mathrm{H}_{2} \mathrm{O}$ & 100 & 85 & 3.75 & 1.85 \\
5. $\mathrm{OsCI}_{3} \times \mathrm{H}_{2} \mathrm{O}$ & 300 & 74 & 4.5 & 1.78 \\
\hline
\end{tabular}

${ }^{a}$ Polymerization was carried out in chlorobenzene for $12 \mathrm{~h}$ at $70^{\circ} \mathrm{C}$, initial monomer (NBC) concentration $-0.5 \mathrm{moll}^{-1}$. ${ }^{\mathrm{b}}$ Monomer to Catalyst mole ratio. " Methanol insoluble polymer. ${ }^{\mathrm{d}} \mathrm{GPC}$ analysis in chloroform with polystyrene calibration standards.

trans double bonds ( $50-60 \mathrm{~mol} \%$ of cis double bonds). The polymerization at high monomer concentration (more than $1 \mathrm{moll}^{-1}$ ) rapidly leads to cross-linked polymer, while decrease in the monomer concentration results in a drastic reduction of the polymer yield. To avoid high catalyst concentration in polymer the reaction carried out by adding of small quantities of $\mathrm{Ru}$ and Os containing catalysts $(0.3-1.0 \%$ in relative to the monomer). Our results suggest that the polymer yield is very sensitive to the monomer/catalyst ratio and increasing this ratio in the case of $\mathrm{Ru}$ based catalysts leads to more rapid reduction of the polymer yield (Table I). The resulting polymer is soluble in chloroform or chlorobenzene, but insoluble in tetrahydrofuran (THF) and benzene. Coumarin-containing polynorbornene is a rubber like matgerial and can be cast from chloroform to a transparent film.

The results obtained by GPC analysis are presented in Table I. The number average molecular weight $\left(M_{n}\right)$ and the polydispersity of the poly(NBC) were found to be $1.2-4.5 \times 10^{5}$ and $1.85-2.1$, respectively.

IR spectra of poly(NBC) showed strong absorption of coumarin carbonyl at $1734 \mathrm{~cm}^{-1}$, aliphatic $\mathrm{CH}$ stretching in the region of $2950-2860 \mathrm{~cm}^{-1}$ and the characteristic bands near $870-970 \mathrm{~cm}^{-1}$ corresponding to the $c i s$ and 
<smiles></smiles>
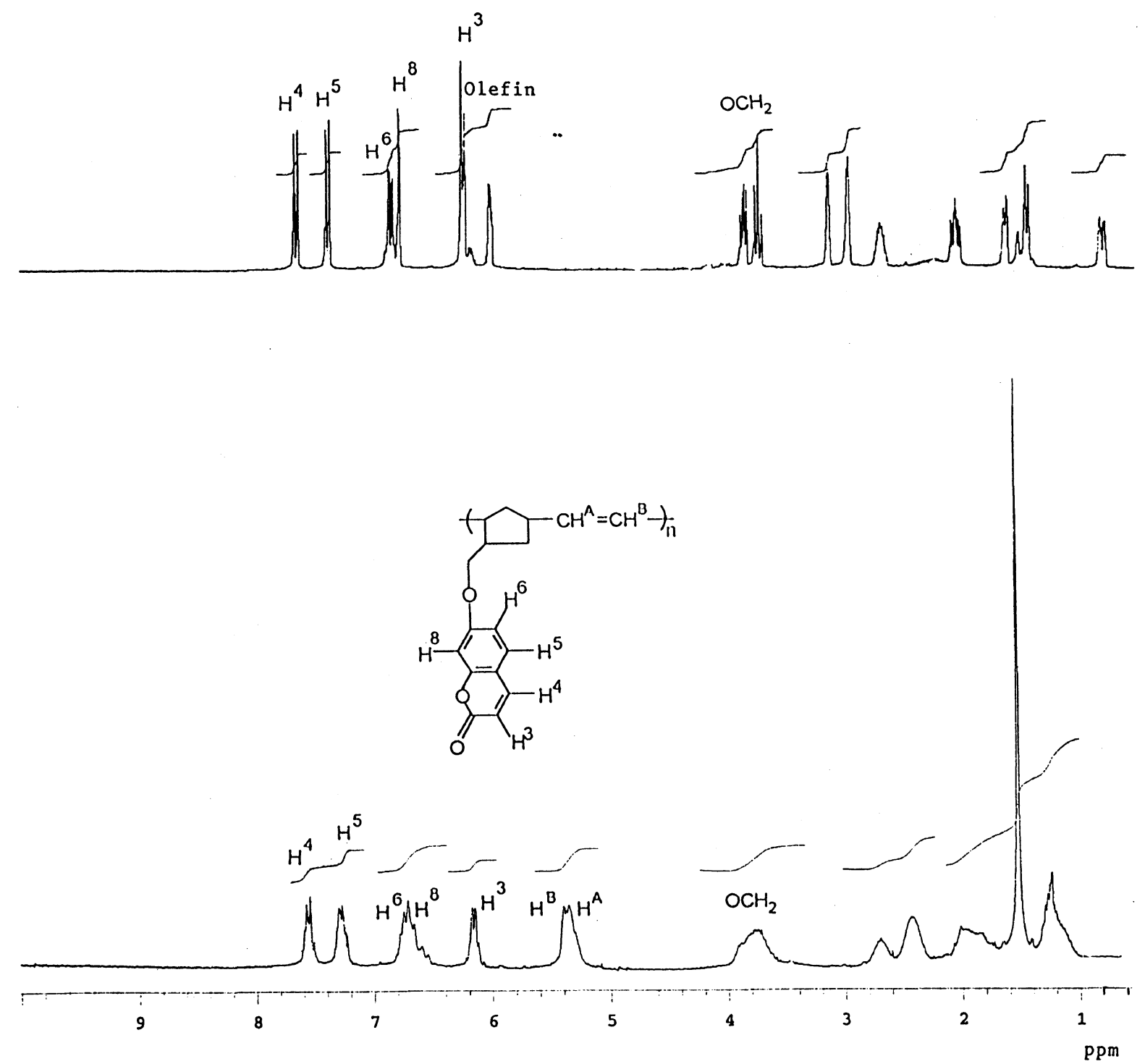

Figure 1. ${ }^{1} \mathrm{H}$ NMR spectra of monomer $(\mathrm{NBC})$ (a) and poly(NBC) in $\mathrm{CDCI}_{3}$ obtained using $\mathrm{RuCI}_{3} \times \mathrm{H}_{2} \mathrm{O}$.

trans double bond of the polymer. ${ }^{11}$ Figure 1 presented ${ }^{1} \mathrm{H}$ NMR spectra of both the monomer (a) and the polymer (b) prepared by $\mathrm{RuCI}_{3} \times \mathrm{H}_{2} \mathrm{O}$ catalyst. The monomer olefinic signals between 5.98 and $6.2 \mathrm{ppm}$ are replaced by a new signal with a maximum $5.35 \mathrm{ppm}$ corresponding to the linear olefinic proteins of the predominant trans double bond of the polymer. ${ }^{11}$ The doublets at 7.62 and $7.35 \mathrm{ppm}$ with $J=9.5$ and $8.5 \mathrm{~Hz}$ corresponded to $\mathrm{H}^{4}$ and $\mathrm{H}^{5}$ of coumarin ring, multipletes at $6.95,6.80$, and $6.23 \mathrm{ppm}$ can be assigned to $\mathrm{H}^{8}, \mathrm{H}^{6}$, and $\mathrm{H}^{3}$, respectively. The ${ }^{13} \mathrm{C}$ NMR spectrum (Figure 2) also agrees with the fact that the obtained by Ru based catalysts polymer contains predominantly trans double bonds and consists of coumarin peaks at $162.5\left(\mathrm{C}^{2}\right)$, $160.8\left(C^{7}\right), 156.0\left(C^{9}\right), 143.3\left(C^{4}\right), 112.9\left(C^{6}\right), 112.8\left(C^{3}\right)$, $101.6\left(\mathrm{C}^{8}\right), 112.5\left(\mathrm{C}^{10}\right)$, four different olefinic carbons of polymer chain at $135.0,135.1,131.4$, and 129.5 corresponding to head to tail and tail to head enhantments along the chain, ${ }^{12}$ signals at 72.2 , and $49.50,-29.1$ correspond to $\mathrm{CH}_{2} \mathrm{O}$ and aliphatic carbons, respectively. 


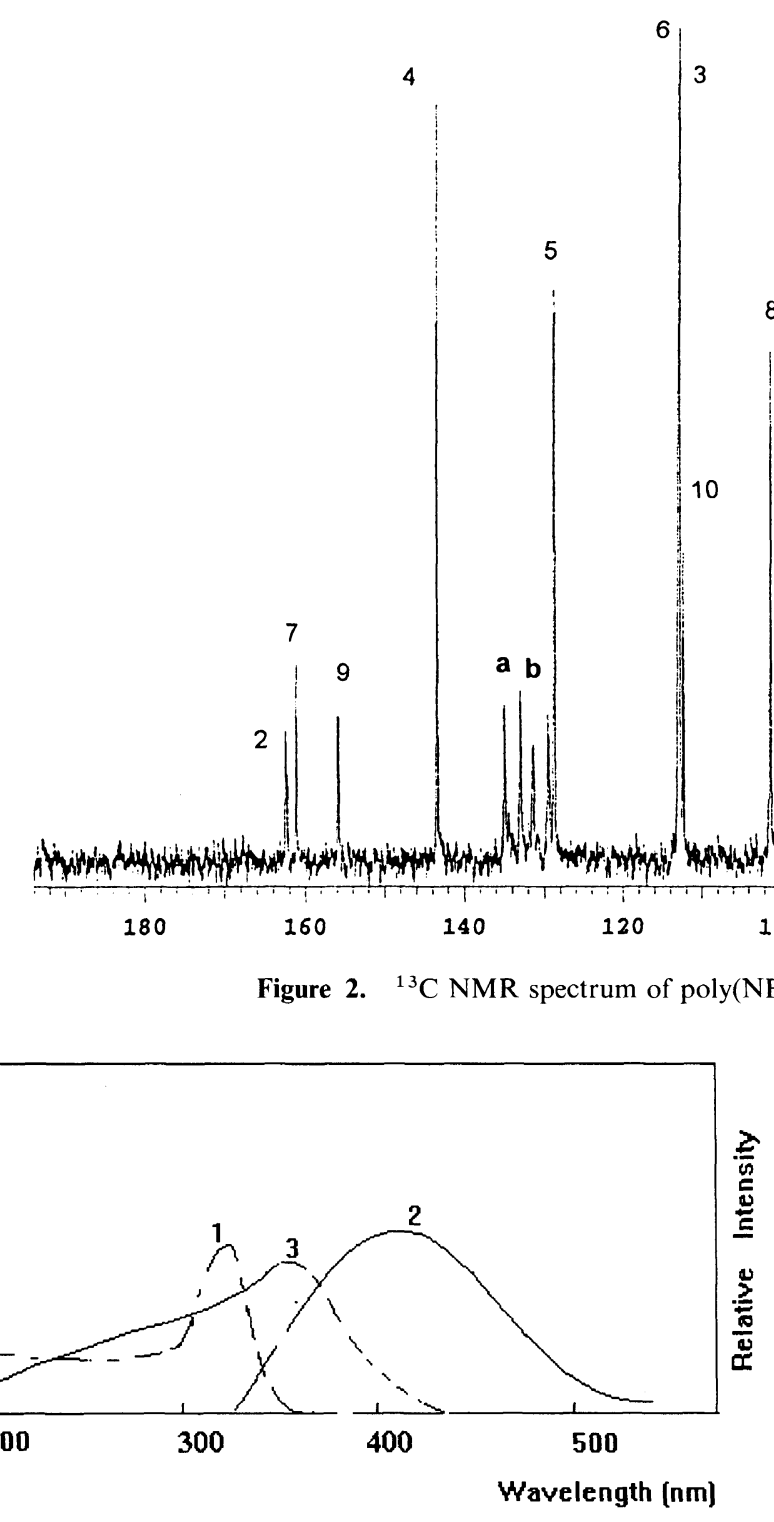

Figure 3. Absorption (1), emission (2), and exitation (3) spectra of poly(NBC).

The X-ray patterns indicate that prepared polymers are predominantly amorphous. The glass transition temperature $\left(T_{\mathrm{g}}\right)$ of the poly $(\mathrm{NBC})$ by DSC and TMA was $67^{\circ} \mathrm{C}$. TGA shows that the poly(NBC) is stable up to $340^{\circ} \mathrm{C}$ in nitrogen atmosphere.

The obtained poly(NBC) showed photoluminescence in solution and films owing to the coumarin fragment. Figure 3 shows absorption and emission and excitation spectra of polymer. Poly(NBC) exhibited long wave absorption maximum at $350 \mathrm{~nm}$ and emits at $\lambda_{\max }=$ $410-420 \mathrm{~nm}$. It is noteworthy that NBS itself shows essentially the same absorption and emission spectra as poly(NBC) thus indicating there is no considerable interaction between coumarin groups in the polymer.

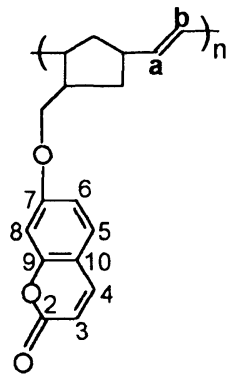

$\mathrm{OCH}_{2}$

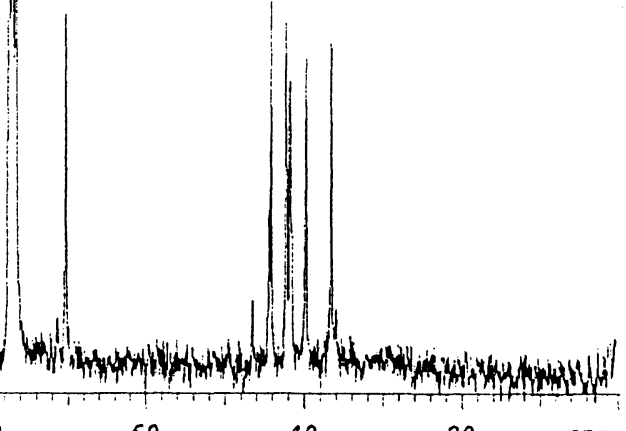

ppm

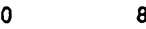

60

40

$\mathrm{I}_{3}$ obtained using $\mathrm{RuCI}_{3} \times \mathrm{H}_{2} \mathrm{O}$

Acknowledgments. This work was supported by the Grant from CONACyT with contract N 0087-PN. Thanks are also due to M. A. Canseco, Ruben Gaviño, E. Miranda, and C. Vazquez for their assistance in UV spectroscopy, NMR-analysis and thermal analysis, respectively.

\section{REFERENCES}

1. T. Yen, M. Davar, and A. Rembaum, J. Macromol. Sci., Chem., 4, 693 (1970).

2. E. Gipstein and W. Hewett, US Patent 3554741 (IBM Corp.) (1971); Chem. Abstr., 74, 93485c (1971).

3. A. Abyshev, Y. Brodskii, P. Denisenko, V. Kropachev, Yu. Melnik, N. Savel'eva, and I. Simonova, Khim. Farm. Zh., 11, 41 (1977); Chem. Abstr., 87, 15688a (1977).

4. H. Patel and S. Patel, J. Macromol. Sci. Chem., A21, 343 (1984).

5. Chen Yun, J. Polym. Res., 1, 295 (1994).

6. D. I. Brahmbhatt and B. R. Hirani, High Perform. Polym., 8, 295 (1996).

7. S. Fomine, L. Fomina, C. Sánchez, A. Ortiz, and T. Ogawa, Polym. J., 29, 49 (1997).

8. J-K. Lee, R. R. Schrock, D. R. Baigent, and R. H. Friend, Macromolecules, 28, 1966 (1995).

9. M. A. Tlenkopatchev, S. Fomin, E. Miranda, L. Fomina, and T. Ogawa, Polym. J., 27, 1173 (1995).

10. J. Asrar, Macromolecules, 25, 5150 (1992).

11. B. Bell, J. G. Hamilton, E. E. Law, and J. J. Rooney, Macromol. Rapid Commun., 15, 543 (1994).

12. M. A. Tlenkopatchev, E. Miranda, M. A. Conseco, R. Gabiño, and T. Ogawa, Polym. Bull., 34, 385 (1995).

13. P. S. Hallman, T. A. Stephenson, and G. Wilkinson, Inorg. Synth., 12, 237 (1970). 